\title{
Probable time and conditions of a coal-seam paleofire in the Upper Silesian Coal Basin, Poland
}

JUSTYNA CIESIELCZUK ${ }^{1}$, JERZY NAWROCKI ${ }^{2}$, DOMINIK JURA ${ }^{1}$, MONIKA J. FABIAŃSKA ${ }^{1}$, MAGDALENA MisZ-KENNAN ${ }^{1}$, PAWEŁ FILIPIAK ${ }^{1}$

${ }^{1}$ University of Silesia, Będzińska 60, 41-200 Sosnowiec, Poland, justyna.ciesielczuk@us.edu.pl

${ }^{2}$ Maria Curie Skłodowska University, Kraśnicka 2 cd, 20-718 Lublin, Poland

A coal seam in the Saddle Beds in the Upper Silesian Coal Basin (Poland) thins and thins out due to a paleofire. The coal type, typically 35.2 , increases to 42 and becomes grey-black and dull where it thins out and vanishes. There, the coal is heavily cracked and brittle and lacks a banded structure. Thermally transformed gangue rocks change in colour to red, yellow and white and display increased fracturing, porosity and reduced physical and mechanical properties. Various types of weathered- and thermally altered rocks with irregular geometries characterize mining areas from the vicinity of Rybnik (Poland) to the Karviná region (Czech Republic). There, thinned-out coal seams inhibit mining operations. The first aim of the study was to establish the cause for seam thinning and disappearance. Possibilities include weathering, thermal- and metamorphic changes at contacts with magma intrusions or endogenous fire. As the first two had been excluded on the basis of XRD, SEM-EDS, Raman spectroscopy, GC-MS, XRF, RLOM, and palynological data, the second aim was to establish, with the addition of paleomagnetic measurements, the conditions and timing of the paleofire that caused the changes in the thinned-out seam. Geochemical-, mineralogical-, petrographical- and palynological investigations established differences in fire intensity, duration and oxygen access. In some areas, seams burned rapidly and intensively with an abundance of oxygen. Others were altered over an extended time under conditions of limited oxygen access. The paleomagnetic signature measured in thermally unaffected clays, which is related to the time of clay deposition, characterizes the original magnetic record of the coal-bearing formations. The natural remanent magnetism of red claystones accompanying the vanishing coal seam, in revealing properties consistent with high temperatures, points to the acquisition of thermoremanent magnetisation. The very steep (ca. $70^{\circ}$ ) inclination of the characteristic component of this magnetisation suggests a Cenozic age for the fire. The history of the coal seams is complex, overprinted by variable weathering and metasomatism.

Funds from project 2016/21/B/ST10/02293, National Science Centre, Poland, are acknowledged. 